\title{
Las relaciones entre Francia y Chile, ayer y hoy
}

\author{
Excmo. Embajador de Francia, Roland Dubertrand*
}

Desearía hacer un recuento histórico de la relación bilateral franco-chilena, situándola en el largo plazo y abordando su actual desarrollo.

Este relato permitirá describir la francofilia chilena, antigua y profunda, que resulta fundamental comprender con el fin de poder apreciar la calidad de la relación bilateral. Pero esto no impide que esta última deba renovarse en el siglo xxi, en función de la evolución trascendental experimentada por ambos países en el transcurso de los últimos decenios. Por otra parte, en el contexto de la actual mundialización, las interacciones concretas se han intensificado, sin considerar otros factores que identificaremos más adelante, $y$ este fenómeno aboga por una relación bilateral moderna y vasta.

\section{I.- LA HERENCIA DEL PASADO: UNA RELACión PRÓSPERA Y ANTIGUA}

Es evidente que la distancia geográfica ha constituido un freno en la relación, pero Francia es considerada en Chile como una referencia mayor, cultural y política, desde inicios del siglo xIx

Roland Dubertrand, asumió como Embajador de Francia en Chile en marzo de 2018. El diplomático francés es ministro plenipotenciario de segunda clase, Caballero de la Legión de Honor y Caballero de la Orden Nacional del Mérito.

Dubertrand es Máster en Derecho Público por el Instituto de Estudios Políticos de Burdeos; ex estudiante de la Escuela Nacional de Administración, promoción "Denis Diderot"; titulado en estudios superiores en Teología y Ciencias de las Religiones en el Instituto Católico de París. a los años 1945-1950, cuando el modelo norteamericano se impone progresivamente. Pero se crean nuevos lazos con la migración chilena ligada al golpe de Estado de 1973, y después con el incremento de los intercambios económicos.

\section{a) El siglo xIx: el apogeo de la influencia francesa en Chile}

Naturalmente hubo contactos durante el período de la colonia española, pero se limitaban a los marinos, navegantes y corsarios, y a los mercaderes franceses que comercializaban en Valparaíso a partir de fines del siglo xvII, 
dos de los cuales fueron grandes exploradores: Bougainville y La Pérouse.

Todo cambia con la Batalla por la Independencia de 1810 a 1818, puesto que Francia implanta el modelo de la emancipación concentrado en la filosofía de las Luces, la Revolución Francesa y la acción épica de Napoleón. "La aventura de los tres Antonios" es la de dos franceses: Antoine Gramuset y Antoine Berney, quienes junto al Chileno Antonio Rojas, prepararon un complot para la independencia y fueron detenidos en 1781. A partir del inicio del proceso de la independencia en 1810, los veteranos de guerra de la Revolución y del Imperio se unen, a título individual, a las tropas de O'Higgins y de San Martín; citemos al coronel Beauchef; al capitán Drouet, hijo del tabernero de Varenne; Benjamin Viel, quien se distingue en la batalla de Maipú, y al alsaciano Crammer.

$\mathrm{Al}$ parecer, a Napoléon le había gustado la idea de ayudar a las nacientes repúblicas latinoamericanas para liberarse, pero la esta no prosperó. Por el contrario, la Francia de la Restauración es aliada de los Borbones de España y hubo que esperar el año 1831 y Louis-Philippe para que Francia reconociese la independencia de Chile, con el nombramiento del Sr. de Cazotte en calidad de encargado de negocios y cónsul general en Santiago. A pesar del incidente de Magallanes en 1843, durante el cual una nave francesa fingió tomar posesión del Estrecho, en 1846 se firmó un tratado de amistad y de comercio.
Para la elite chilena proveniente de la independencia, Francia servirá de modelo político, jurídico y cultural de manera ampliamente exclusiva hasta los años 1880-1890, luego compitiendo con Alemania hasta el año 1945; la influencia británica se hizo sentir principalmente en el mundo de los negocios. Basta evocar el nombre de Claude Gay, quien recorre Chile desde 1828 hasta 1842 como geógrafo, botánico y naturalista, bajo la autoridad de Diego Portales, y publica la monumental Historia Física y Política de Chile, participando de ese modo en la construcción de la identidad nacional moderna del país. La arquitectura de Santiago se encuentra muy influenciada por Francia a través de los arquitectos franceses: François Brunet por la construcción del Teatro Municipal y Lucien Hénault, por la Cámara de Diputados y la Universidad de Chile. El Museo de Bellas Artes fue construido en 1880 por un arquitecto chileno, pero también siguiendo el modelo francés. Las elites se constituyen con frecuencia en las escuelas católicas francesas, como aquellas de la Congregación del Sagrado Corazón de Jesús y María. Por último, la influencia en la literatura y la filosofía está omnipresente, como lo demuestra la obra del filósofo positivista José Victorino Lastarria. La Alianza Francesa se instala en 1891-1894 y crea las escuelas francesas, la primera de ellas en Traiguén.

Esta evidente influencia es apoyada por una comunidad francesa poderosa, constituida por 10.000 miembros en 
1900, cuyo desarrollo fue narrado por el Sr.Jean-Pierre Blancpain en su obra "Chile y Francia". El flujo de inmigrantes, formado por aproximadamente 20.000 y 25.000 personas entre 1840 et 1940, provienen principalmente de los Pireneos y de la costa atlántica, entre los cuales había refugiados políticos. Los franceses se instalan como comerciantes e industriales activos en Valparaíso y Santiag, y también en las viñas y la agricultura en la región central y el Bío-Bío. Las familias originarias del país vasco lo hacen especialmente en la curtiembre y la viña, e impulsan notablemente la viticultura chilena. La comunidad es influyente y organizada y la primera compañía de bomberos "Pompe France" se forma en Valparaíso en 1856 y luego en Santiago, en 1864. La Cámara de Comercio franco-chilena, aún activa, se crea en 1883. En la actualidad, se calcula que existe un número aproximado de 500.000 chilenos descendientes de inmigrantes franceses.

Un episodio romanesco habría podido opacar esta relación de confianza: se trata de la aventura de Antoine de Tounens, asistente de notaría en Périgueux, quien se proclama Rey de la Araucanía y de la Patagonia entre 1860 y 1862, obteniendo la adhesión de los jefes indígenas. El será expulsado por las autoridades chilenas en 1862. Entonces estas últimas toman conciencia de la precariedad de su control en el sur, lo cual impulsará la ocupación de la región mapuche, finalizada en 1883 , y la penetración progresiva de la Patagonia. Chile unirá Isla de Pascua en
1888 con el acuerdo de Francia, quien posee la vecina Polinesia francesa.

\section{El XXème siglo: competencia alemana y hegemonía americana}

A partir de 1885, el Ejercito y la Armada de Chile reciben instructores alemanes, quienes reemplazan la colaboración militar francesa, predominante hasta esa fecha. En muchos ámbitos y hasta el año 1945, ambos países serán rivales en Chile, mientras que la presencia francesa se debilita relativamente después de la Primera Guerra Mundial, durante la cual Chile permanece neutro. Sin embargo, la epopeya de Aéropostale, con sus hazañas aéreas, llega al país en 1929. Aunque su posisión económica dismimuye, Francia continúa siendo un gran referente cultural, según lo demuestran los lazos que estrecharon con ella los poetas Vicente Huidobro y, por cierto, Pablo Neruda, quien posteriormente será nombrado Embajador en París, bajo el Gobierno de la Unidad Popular.

La Segunda Guerra Mundial, conflicto en el cual Chile participa a partir de enero de 1943, aunque sin compromiso militar directo, confirma el declive de la presencia de Francia tras el impacto de la derrota de 1940, la disminución de los intercambios económicos y el ascenso irresistible del poderío e influencia de los Estados Unidos. Sin embargo, Chile efectivamente es uno de los países de América Latina donde se forman - especialmente gracias a la acción del Sr.Jean Muzard - el mayor 
número de comités de la Francia libre, los cuales contarán hasta 7.000 adherentes. Una entusiasta marea humana es la que invade las calles de Santiago ante el anuncio de la liberación de París, en agosto de 1944.

La posguerra está marcada por el nombramiento, en 1945, del primer embajador en ejercicio, el Sr. de Dampierre y, en particular, por la memorable visita del General de Gaulle en 1964. Francia, cuya enseñanza del idioma fue durante largo tiempo obligatoria, se esfuerza por conservar su posición frente al modelo americano triunfante, aquí como en otros lugares.

El Golpe de Estado del 11 de septiembre 1973 modificará la situación, luego de tres años de gobierno de Unidad Popular, seguidos de cerca por la izquierda francesa. La embajada y la residencia acogen, entre septiembre de 1973 y julio de 1974, a 600 chilenos que huyen de la represión, bajo la responsabilidad de Pierre de Menthon, embajador en esa época y de su esposa Françoise. Francia recibirá un total de 15.000 réfugiés chilenos, a los cuales brindará asilo político y será el país que, en un primer momento junto a Suecia, habrá acogido la mayor cantidad de refugiados en Europa. Esta presencia humana creará múltiples y renovados lazos, los que aún están latentes en nuestra cooperación bilateral.

En 1973, Francia -que reconoce a los Estados no así a los gobiernosno había condenado el régimen militar en su calidad de tal, pero se mostrará cada vez más crítica frente a las violaciones de los derechos humanos, período durante el cual el Instituto Cultural en Santiago se convirtió en un espacio de libertad valorado. La distancia se profundizará en 1981 con la llegada al poder de François Mitterrand y de los socialistas, muy solidarios de la izquierda chilena en el exilio. El retorno de la democracia, en 1990, mostrará la reapertura internacional del país y un vuelco de Francia para apoyar la transición a nivel político, económico y de cooperación, todo ello dentro del contexto de la nueva mundialización.

\section{II.- LA ACTUAL RELACIÓN BILATERAL}

A partir de 1990, la relación bilateral se impulsó sobre renovadas bases, retomando, en parte, la herencia precedente. Aunque Francia perdió su rol como una referencia dominante, ella representa, después de España y junto a Alemania, uno de los principales socios europeos, del país cuyas relaciones internacionales se equilibran entre Estados Unidos, la región Asia-Pacífico y Europa, además de sus vecinos latinoamericanos. Para Francia, Chile también representa un socio confiable e importante en la región, después de los grandes países: México y Brasil. 


\section{Las relaciones políticas y militares}

El apoyo a la transición democrática chilena se tradujo por un incremento de los intercambios de todo tipo y, en particular, políticos, a través de las visitas oficiales a Francia de los Presidentes Aylwin en 1992; Frei en 1997; Lagos en 2001; Bachelet en 2009, y Piñera en 2010, y de la visita oficial del Presidente Jacques Chirac a Chile, en 2006.

Al respecto, estos últimos años han marcado una reactivación debido a las visitas oficiales a Francia realizadas por la Presidenta Michelle Bachelet en el 2015; por el Presidente François Hollande a Chile en 2017 y por Sebastián Piñera a París en 2018, con ocasión de la cual se adoptó una declaración con una hoja de ruta bilateral. El ritmo del diálogo político de alto nivel se intensificó, de lo cual hasta el momento carecía la relación franco-chilena, a pesar de las constantes consultas políticas.

Haciendo referencia a la última visita oficial a París, el 8 de octubre 2018, se constata que los Señores Emmanuel Macron y Sebastián Piñera reafirmaron, además de la prioridad otorgada a la innovación y a la economía digital para el desarrollo a futuro de la relación, su compromiso con la defensa del sistema multilateral actualmente amenazado. Ambos países desean trabajar en conjunto, especialmente acerca de asuntos relativos a la protección del medio ambiente y del cambio climático (mientras que Chile será sede de la COP 25 en diciembre de 2019).
Asimismo, la cooperación militar y estratégica se desarrolló, en especial la relación entre las dos armadas navales, con intereses comunes de seguridad en el Pacífico Sur y la adquisición, por parte de Chile, de dos submarinos Scorpène en 1998. Es preciso recalcar, además, que los dos países son "Estados con posesión" en la Antártica, continente desmilitarizado mediante el Tratado de Washington de 1959.

\section{Los intercambios económicos y comerciales}

Estos experimentaron una verdadera aceleración en el contexto de la mundialización, la cual creó nuevos lazos entre Europa y América Latina. De este modo, en 2017, Chile se transformó en el 20 cliente de las exportaciones francesas en América del Sur, después de Brasil y antes que Argentina. Los intercambios han alcanzado dos mil millones de euros y son relativamente equilibrados, Francia $(975 \mathrm{mi}-$ llones en exportaciones) adquiriendo principalmente cobre y Chile (1089 millones en exportaciones) diversos bienes de capital y de consumo.

Las inversiones francesas en Chile alcanzan 3 mil y medio millones de euros (y probablemente 8 mil millones tomando en cuenta las inversiones indirectas), lo que sitúa a Francia como el segundo inversionista europeo en el país. 240 filiales de empresas francesas están presentes en Chile, en particular en los sectores de transporte (Airbus, 
Alstom, PSA, Renault); de infraestructuras (Vinci, $A D P$ ); de energía (Engie, EDF, Total); de ciudad sostenible (Suez), y de comunicaciones (Thalès). También resulta interesante observar el inicio de las inversiones chilenas en Francia (grupos Luksic y Sigdo Koppers).

Con el fin de apoyar la implantación de las empresas francesas en Chile, la red económica francesa está organizada alrededor del servicio económico de la embajada, de la oficina Business France, de la Cámara de Comercio franco-chillena y de los consejeros del comercio exterior. Es indudable que Francia se ha visto favorecida por la política de apertura comercial dinámica conducida por Chile desde 1990 y de la firma de un acuerdo de asociación con la Unión Europea en 2002, el cual se encuentra actualmente en proceso de renegociación.

De este modo, nuestro país se convirtió en el tercer exportador europeo hacia Chile, después de España y Alemania.

\section{La cooperación cultural, cientifica y técnica}

Esta colaboración es especialmente densa y diversa, y ella ha alcanzado un nivel de madurez notable, pero con nuevos desafíos por enfrentar.

La cooperación científica y universitaria es el foco central y ella está piloteada, así como otras colaboraciones, por el Instituto Francés de Santiago, el cual también es parte integrante de la embajada. Entre nuestros dos países existen 700 acuerdos de cooperación universitaria y 15 laboratorios de investigación y centros de excelencia comunes (matemáticas, numérica, biología, energías marinas, astronomía, inter alia). Recientemente fue creado un centro franco-chileno de Altos Estudios para coordinar la colaboración emprendida con la Universidad de Chile y el programa ecos, que permite sustentar numerosos programas de investigación bilaterales. Asimismo, la movilidad estudiantil entre ambos países es considerable contabilizando 900 estudiantes chilenos en Francia y 600 estudiantes franceses en Chile. El gobierno francés además se preocupa de atraer más estudiantes chilenos con alta formación para el nivel master y doctorado.

La cooperación educativa y lingüística es esencial. Existen cinco liceos franceses en el país, convencionados o en directa colaboración con la Agencia para la Enseñanza del Francés en el Extranjero ( $A E F E$ ) en Santiago, Viña del Mar, Concepción, Osorno y Curicó, escolarizando alrededor de 7.000 alumnos, muchos de los cuales continúan la enseñanza francesa hasta el bachillerato. Además, en el Instituto Francés se dictan cursos de francés en Santiago, al igual que en siete Alianzas Francesas en regiones (Valparaíso, Concepción, Antofagasta, La Serena, Osorno, Valdivia y Rapa Nui). El 
idioma francés también se enseña en las escuelas internacionales y privadas, no siendo así en el sistema secundario público, el cual pasó a "inglés-total" a fines de los años' 90.

Como consecuencia de la visita oficial del 8 octobre 2018, las autoridades francesas propusieron a las autoridades chilenas la reintroducción del francés como idioma optativo en el ciclo secundario. Si en ese sentido no se hace un sólido esfuerzo, la francofonía se verá gravemente amenazada en Chile en el transcurso de los próximos años y las jóvenes generaciones corren el riesgo de perder contacto con nuestro país y su cultura.

\section{Conclusión}

En base a este panorama, ¿cómo calificar en la actualidad la relación franco-chilena? Una visión pesimista podría poner énfasis en el obstáculo persistente del distanciamiento geográfico, incluso geopolítico, entre ambos países. Chile tiene como primer colaborador estratégico a los Estados Unidos y ha volcado cada vez más su interés hacia Asia, siendo la Unión Europea su tercer colaborador comercial y Francia, el tercero dentro de los países europeos. Por otra parte y de acuerdo a esta visión desmovilizadora, Francia nunca otorgó una verdadera prioridad política a América Latina, que pasaría a ubicarse después de Europa, Medio Oriente y Africa, en ese orden, de acuerdo a sus preocupaciones estratégicas.

Sin embargo, me gusta citar a Alain Rouquié, quien manifiesta que la presencia francesa en América Latina, cimentada piedra a piedra y profundamente desde el siglo xIx, no debe ser juzgada en función de la actualidad inmediata. Ella está constituida por múltiples colaboraciones, el rol del idioma y de la cultura, de los valores y batallas compartidas, de reales afinidades.

Hemos precisado que Chile se convirtió en nuestro segundo cliente en América del Sur, fenómeno ligado al desarrollo del país y a su estabilidad, y hemos constatado que las relaciones de cooperación cultural y científica son muy densas. Aún hay mucho trabajo por hacer en el futuro, a condición de responder al mayor desafío: el de la decadencia del francés en la región y en Chile.

Es más, cuando el unilateralismo, el populismo y el autoritarismo ganan terreno en el mundo, Europa y América Latina; Francia y Chile, comparten los mismos valores en defensa de la democracia, del multilateralismo y de la cooperación internacional. Particularmente frente al cambio climático, el 
desafío es actuar siempre en conjunto, a nivel multilateral y bilateral.

La participación del Presidente Sebastián Piñera durante el G7 de Biarritz, en agosto pasado, y la actuación común de los dos países durante la Cumbre de las Naciones Unidas sobre el Clima, en septiembre, han resuelto una nueva y estrecha cooperación entre los dos países en favor de una causa global: la lucha contra el cambio climático, por el bien de la humanidad entera. 